\title{
SOLVENT EXTRACTION AND ADSORPTION TECHNIQUE For THE TREATMENT OF Pesticide EFfLUENT
}

\author{
Aswathy Rajan ${ }^{1}$, Sanju Sreedharan ${ }^{2}$ and Dr.V.Babu ${ }^{3}$ \\ ${ }^{1}$ Department of Civil Engineering, SSET, Cochin \\ ${ }^{2}$ Associate Professor, Department of Civil Engineering, SSET \\ ${ }^{3}$ Development Chemist, Hindustan Insecticide Limited, Cochin
}

\begin{abstract}
Solvent extraction and adsorption techniques are effective methods for the removal of pesticides like DDT and Dicofol from the waste water. Study was conducted using 3 different solvents- Ethylene dichloride $(E D C)$, Monochlorobenzene $(M C B)$ and Hexane to optimise parameters like effluent to solvent ratio, agitation speed, agitation time and settling time to attain maximum removal of pesticides by solvent extraction process. MCB was found to be the best solvent when compared to other two solvents using the optimised parameters. The activated carbon $(8 \times 30)$ is an effective adsorbent for the removal of DDT and Dicofol. The material have good adsorptive capacity and follows Freundlich model. The optimum adsorbent dose was observed as $2 \mathrm{gm} / 100 \mathrm{ml}$ and optimum contact time needed to reach the equilibrium was observed as $3 \mathrm{hr}$. Column study was conducted with the synthetic effluent after solvent extraction. Combination of solvent extraction process and adsorption technique was very effective for the removal of Dicofol and DDT with an efficiency of $99 \%$ and $97 \%$ respectively.
\end{abstract}

\section{KEYWORDS}

DDT, Dicofol, Solvent extraction, Pesticide Effluent, Activated Carbon

\section{INTRODUCTION}

Pesticide pollution in surface and ground water has become a major problem today. India is the largest producer of pesticides in Asia and ranks twelfth in the world for its usage. Pesticides can have many benefits and lead to better crop harvests. They can also help to limit the health dangers that insects carrying diseases pose to humans. But indiscriminate use of pesticides becomes harmful to environment as well as to human being. They are persistent organic pollutant and accumulate in fatty tissues. Proper treatment methods are essential before the discharge of pesticide containing effluent from industries to yield rapid improvement in water quality and thereby protect human and aquatic life. For a pesticide manufacturing industry, recovery processes like solvent extraction is efficient since it recover one or more wastewater constituents. The recovered chemical value helps to offset the cost of treatment or can even provide a net benefit [1]. In solvent extraction process, there may be three major operations. First is the extraction in which the solute is transferred from water to the solvent. The second is the solute removal stage in which the solute is separated from the solvent and the solvent is recycled to the extractor. Third is the solvent recovery stage in which the solvent may be removed from the wastewater raffinate [2]. Adsorption is one of the most effective processes of advanced wastewater treatment technologies that industry and academic researchers widely employ for removal of various pollutants. Activated carbon is one among the most widely investigated 
adsorbent in water treatment process [3]. It is a surface based process in which the adsorbate is held onto the surface of adsorbent by Vander waals forces. It may also occur due to electrostatic attraction and chemical bonding. It is one of the well-known method used in the removal of hazardous compounds from polluted waters $[4,5,6]$. But it is too expensive for concentrated waste water because of high bed loading involved; such cases would require either a large bed (high capital investment) or frequent regeneration (high operating cost)[1]. Therefore the combination of solvent extraction process and adsorption technique could be very effective in removing pesticides from pesticide containing effluent.

\section{MATERIALS AND METHODS}

\subsection{Solvent Extraction}

\subsubsection{Preparation of Synthetic Effluent}

Synthetic effluent containing DDT and Dicofol were prepared from the stock solution of $100 \mathrm{ppm}$ each. $20.15 \mathrm{ml}$ of $100 \mathrm{ppm}$ standard DDT stock solutions and $4.6 \mathrm{ml}$ of 100ppm standard Dicofol stock solutions prepared are pipetted in calibrated 5L flask, which was then diluted to the mark with distilled water to obtain the concentrations $403 \mathrm{ppb}$ and $93 \mathrm{ppb}$ of Dicofol and DDT respectively. This was used for the study of removal of pesticides using solvent extraction. The quantification of the pesticides were performed with Agilent Gas Chromatograph (GC) fitted with electron capture detector [ECD]. Three different solvents selected for the study were Ethylene dichloride (EDC), Monochlorobenzene (MCB) and Hexane.

\subsubsection{Experimental Procedure}

The experimental work for this study was carried out at a lab scale reactor. Synthetic effluent and solvents were taken in a round bottom flask and was agitated using an agitator. After agitation, the mixture was transferred to a separating funnel for settling and the solvent occupied upper or lower layer based on its specific gravity. After providing the necessary settling time, the synthetic effluent is separated from the solvent and DDT and Dicofol were extracted from this aqueous solutions using n-hexane .The extracts were then used for quantification of DDT and Dicofol by gas chromatography using electron capture detector. The solvent can be reused after distillation. This procedure is same for all the three solvents for optimising the parameters like agitation speed, effluent to solvent ratio, agitation time and settling time.

\subsection{Adsorption}

\subsubsection{Materials}

The granular activated carbon supplied by M/s. Indo German Company, Cochin was used for this study. These are produced from selected grades of quality coconut shell charcoal so as to have high density, high surface area and low ash content. Two different type of carbon considered were: 12 x 40 US MESH and 8 x 30 US MESH. 
Civil Engineering and Urban Planning: An International Journal (CiVEJ) Vol.3, No.2, June 2016

\subsubsection{Experimental Methods.}

The carbon was washed thoroughly with distilled water to remove the fine particles. The washed carbon dried at $110{ }^{\circ} \mathrm{C}$ for 10 hours and cooled in a desiccator to room temperature was used Batch experiments were performed using a series of sample bottles of $500 \mathrm{ml}$ capacity with glass stoppers and $100 \mathrm{ml}$ of distilled water was taken in each of the bottles. The sample bottles containing pesticides spiked synthetic water samples of $1000 \mu \mathrm{g} / \mathrm{l}$ concentration and the adsorbents were shaken on a mechanical shaker at $150 \mathrm{rpm}$. The experiments are conducted for duration of $2 \mathrm{hrs}$ and then analysed in gas chromatography for the quantification of DDT and Dicofol for the selection of suitable adsorbent and for the optimisation of amount of carbon for the adsorption studies.

Kinetic study was carried out using the same procedure as that of the selection of suitable adsorbent for the studies but the experiments was carried out with the optimum amount of adsorbent and conducted for a duration of $24 \mathrm{hrs}$ at room temperature and the samples were collected every $30 \mathrm{~min}$ up to first $120 \mathrm{~min}$, then every $60 \mathrm{~min}$ up to $360 \mathrm{~min}$ and final sample were collected at $12 \mathrm{hrs}$ and $24 \mathrm{hrs}$. Adsorption studies were also conducted for the development of adsorption isotherms under same experimental condition (pH-6.5, adsorbent size- 8 × 30 and temperature - room temperature). For this, batch experiments were conducted using Erlenmeyer flasks of $500 \mathrm{ml}$ capacity with glass stoppers used in all the experiments. Pesticides spiked synthetic water samples of $0.2,0.4,0.6,0.8,1,1.2,1.4,1.6,1.8$ and $2 \mathrm{mg} / 100 \mathrm{ml}$ concentration were taken in different bottles and optimum amount of carbon was added to each of the bottle. The sample bottles were shaken on a mechanical shaker at $150 \mathrm{rpm}$. After required equilibrium time, the samples were withdrawn from the shaker and extracted for analysis.

Finally, column study was conducted with the synthetic effluent which was treated by solvent extraction process using the best solvent selected. The column was made of sintered glass which had diameter of $1.5 \mathrm{~cm}$ and $70 \mathrm{~cm}$ length. Column was packed with the selected activated carbon above a perforated supporting grid. The particles were first soaked in distilled water to avoid entrapping of air bubbles inside carbon particles and agitated until no air bubbles were detected in the solution. Synthetic effluent was allowed to pass through the column downwards from an overhead separating funnel of capacity 2 litre. Flow to the column was adjusted by operating a valve at the bottom of the separating funnel. The flow from the separating funnel was turned on at time zero and the column was allowed to fill up to the top level of the carbon bed and bottom valve of the glass column was adjusted to get the desired out flow. The study was conducted by filling carbon up to a depth of $50 \mathrm{~cm}$ and with a fixed flow rate of $1 \mathrm{ml} / \mathrm{min}$. Samples were collected at regular time intervals and tested for the pesticides present in the solution after adsorption

\section{RESULTS AND DISCUSSIONS}

\subsection{Results of Solvent Extraction Studies}

\subsubsection{Study on Optimization of Agitation speed}

Three different agitation speeds were taken- $50 \mathrm{rpm}, 80 \mathrm{rpm}$ and $120 \mathrm{rpm}$ to study the effect of agitation speed in solvent extraction process. $80 \mathrm{rpm}$ was observed to be the optimum agitation speed as there was phase separation occurring between the two layers, the formation of emulsion was less and proper mixing of synthetic effluent and solvent took place. 


\subsubsection{Study on Optimization of Effluent to Solvent Ratio}

The study of synthetic effluent to solvent ratio on the extraction of pesticides from synthetic effluent was carried out by varying the synthetic effluent to solvent ratios from 10:1 to 10:3. This study was done at room temperature with optimised agitation speed and other parameters kept constant.

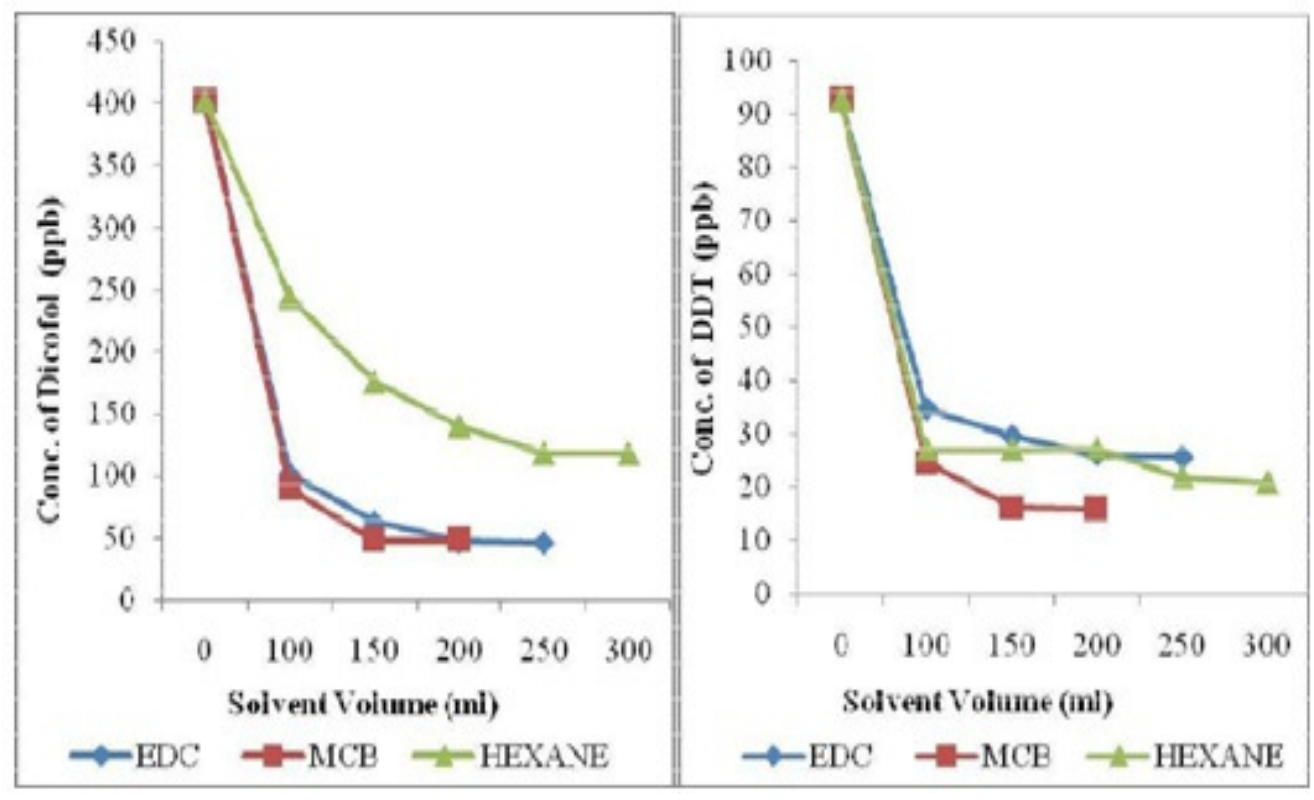

Figure1. Pesticide concentration corresponding to different volumes of solvent

From figure 1: it was observed that increase in the volumes of solvent increases the extraction of pesticides from the synthetic effluent and it was found that optimum effluent to solvent ratio for EDC, MCB and Hexane were 10:2, 10:1.5 and 10:2.5 respectively. After these ratios, extraction had almost reached the saturation value. Therefore, when effluent to solvent ratio was considered, $\mathrm{MCB}$ was found to be the best solvent as it required only $150 \mathrm{ml}$ of solvent for 1 litre of synthetic effluent when compared to the other two solvents.

\subsubsection{Study on Optimization of Agitation Time}

The study of agitation time on the extraction of pesticides from synthetic effluent was carried out by varying the agitation time from $10 \mathrm{~min}$ to $2 \mathrm{hr}$. This study was done at room temperature with optimised agitation speed and optimised effluent to solvent ratio and the other parameters kept constant. 

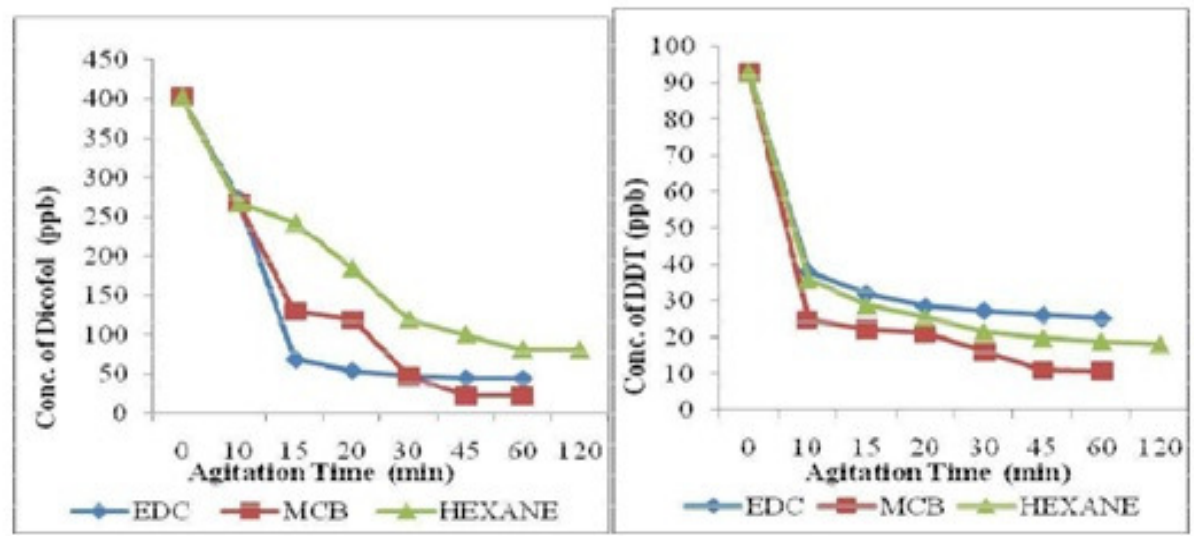

Figure 2. Pesticide concentration corresponding to different agitation time

From Figure 2, it was observed that increase in agitation time increases the extraction of pesticides. For DDT and Dicofol, optimum agitation time was found to be $45 \mathrm{~min}$ when EDC and MCB were used and $1 \mathrm{hr}$ for hexane. After this time, extraction of pesticides had almost reached the saturation value.

\subsubsection{Study on Optimization of Settling Time}

The study of settling time on the extraction of pesticides from synthetic effluent was carried out by varying the settling time from $10 \mathrm{~min}$ to $2 \mathrm{hr}$. This study was done at room temperature with optimised agitation speed, optimised effluent to solvent ratio and optimised agitation time. From Figure 3, it was observed that increase in settling time increased the extraction of pesticides. Optimum settling time was found to be $1 \mathrm{hr}$ for all the 3 solvents. After this time, extraction of pesticides had almost reached the saturation value. Percentage removal of Dicofol and DDT using three solvents with optimised parameters are shown in figure 3.

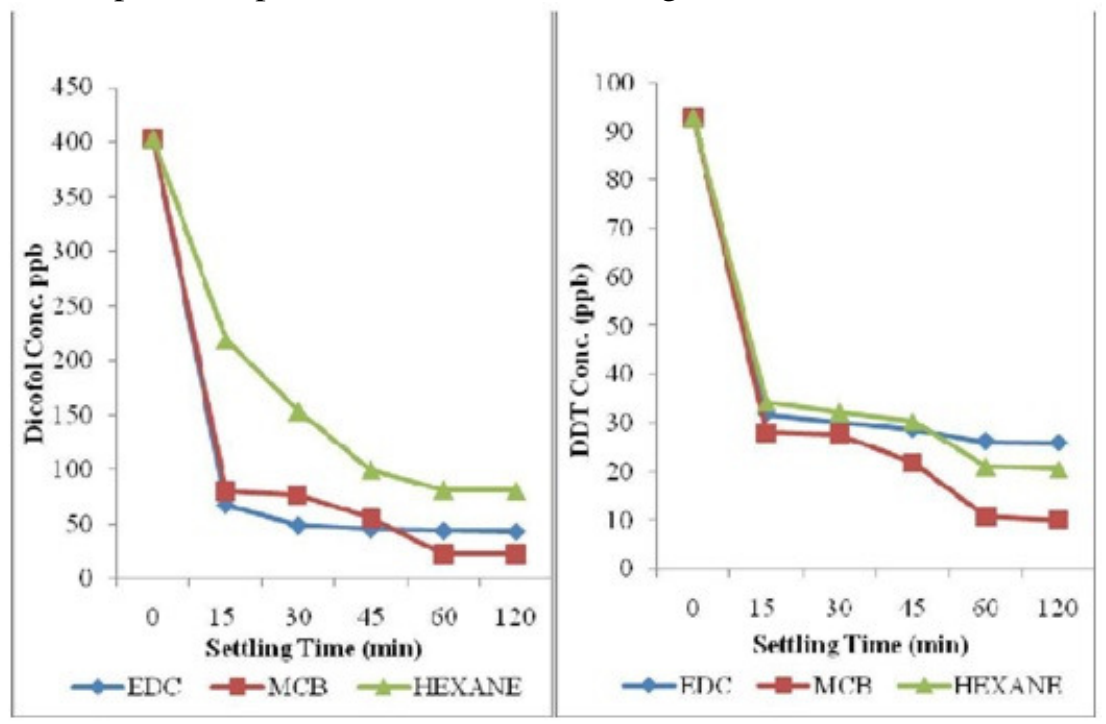

Figure 3. Pesticide concentration corresponding to different settling time 
Based on the optimisation study using different solvents like ethylene dichloride, monochlorobenzene and hexane with different parameters like agitation speed, effluent to solvent ratio, agitation time and settling time, it was observed that monochlorobenzene was found to be the best solvent with a percentage reduction of $94.54 \%$ and $89.2 \%$ for Dicofol and DDT respectively, which was higher than that of the other two solvents. Comparison of percentage removal using three different solvents with optimised parameters is shown in figure 4.

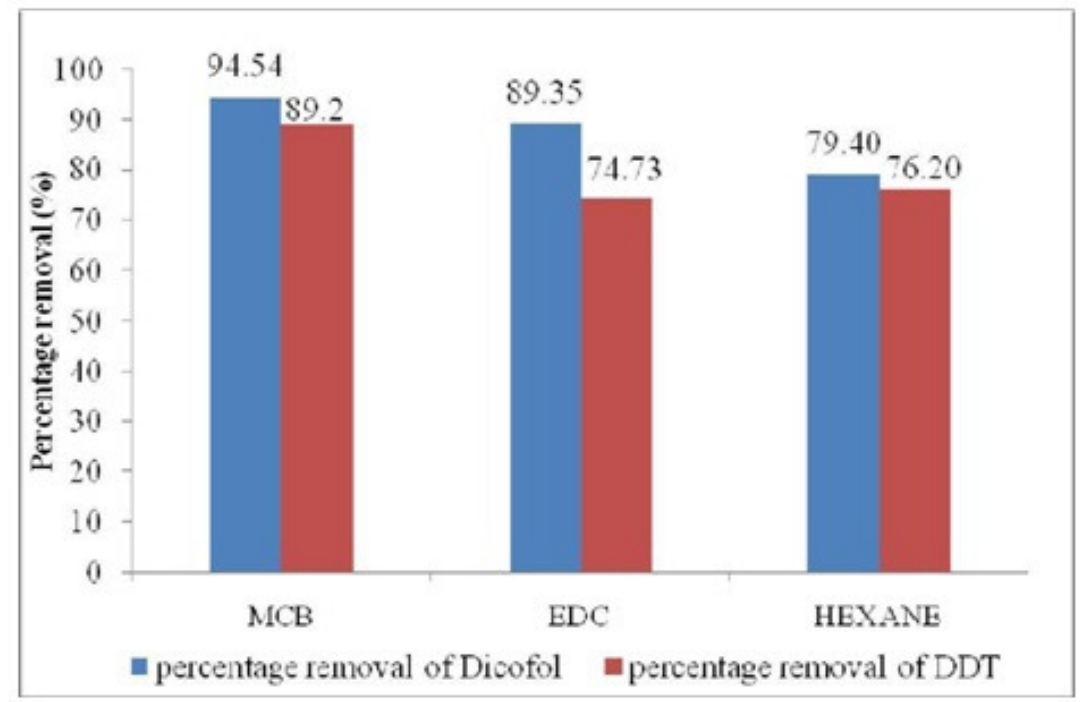

Figure 4. Percentage removal of Dicofol and DDT using three solvents with optimised parameters

\subsection{Results of Adsorption Technique}

\subsubsection{Selection of Suitable Adsorbent}

The percentage removal of Dicofol and DDT using activated carbon ( 8 x 30 US MESH) were $92.61 \%$ and $92.51 \%$ respectively which was higher than that of activated carbon $(12 \times 40 \mathrm{US}$ MESH ). Therefore, $8 \times 30$ grade activated carbon was found to be a good adsorbent and was selected for further studies. 
Civil Engineering and Urban Planning: An International Journal (CiVEJ) Vol.3, No.2, June 2016

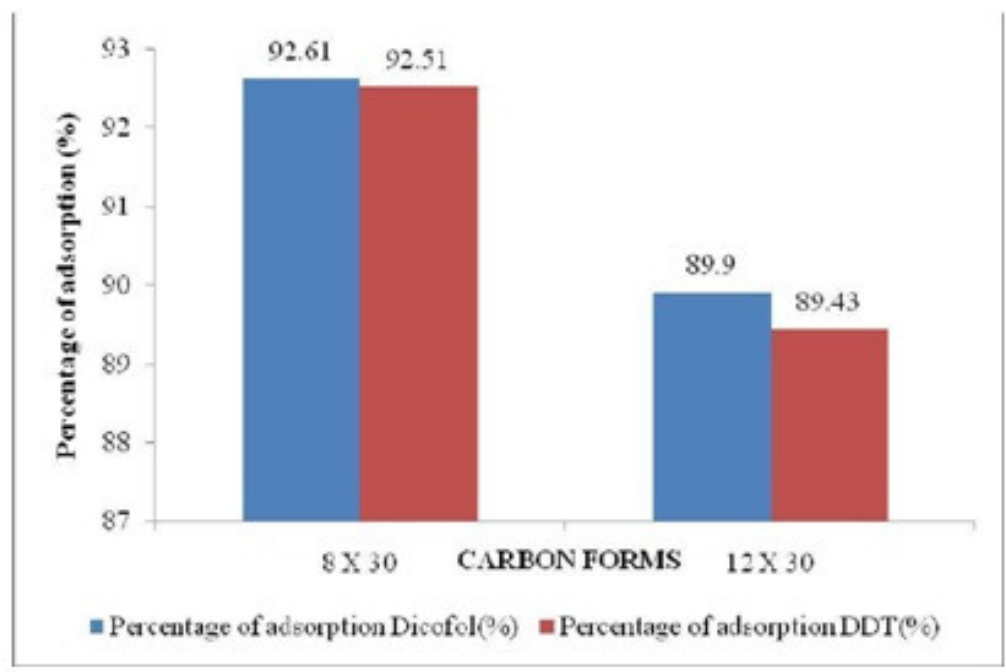

Figure 5. Percentage of adsorption of pesticides using different forms of activated carbon

\subsubsection{Optimisation of Amount of Carbon.}

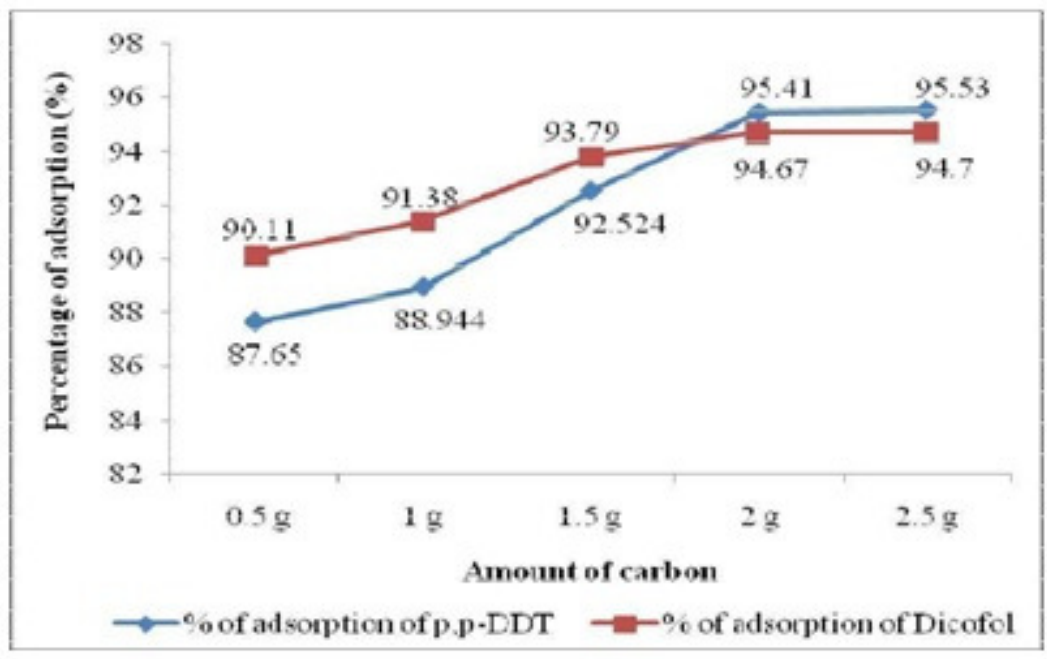

Figure 6.Percentage adsorption of Dicofol and DDT corresponding to different amount of carbon

Optimisation of amount of carbon was done by varying the carbon amount from 0.5 gm to $2.5 \mathrm{gm}$ and it was observed that $2 \mathrm{gm}$ was found to be the optimum amount of carbon with percentage removal of $94.67 \%$ and $95.41 \%$ for Dicofol and DDT respectively.

\subsubsection{Kinetic Studies}

Kinetic studies were done to obtain the equilibrium time. The study was conducted for duration of 24 hours with the influent concentration of $1 \mathrm{mg} / \mathrm{l}$. It was found that the percentage of adsorption increases with increase in time and equilibrium was reached at $3 \mathrm{hr}$ for both Dicofol and DDT. A 
major part of adsorption took place at 1-3 hr after which removal rate was decreased. . Activated carbon ( $8 \times 30)$ removes $99.38 \%$ of pesticides from water in $24 \mathrm{hr}$ of study because of its large surface area.

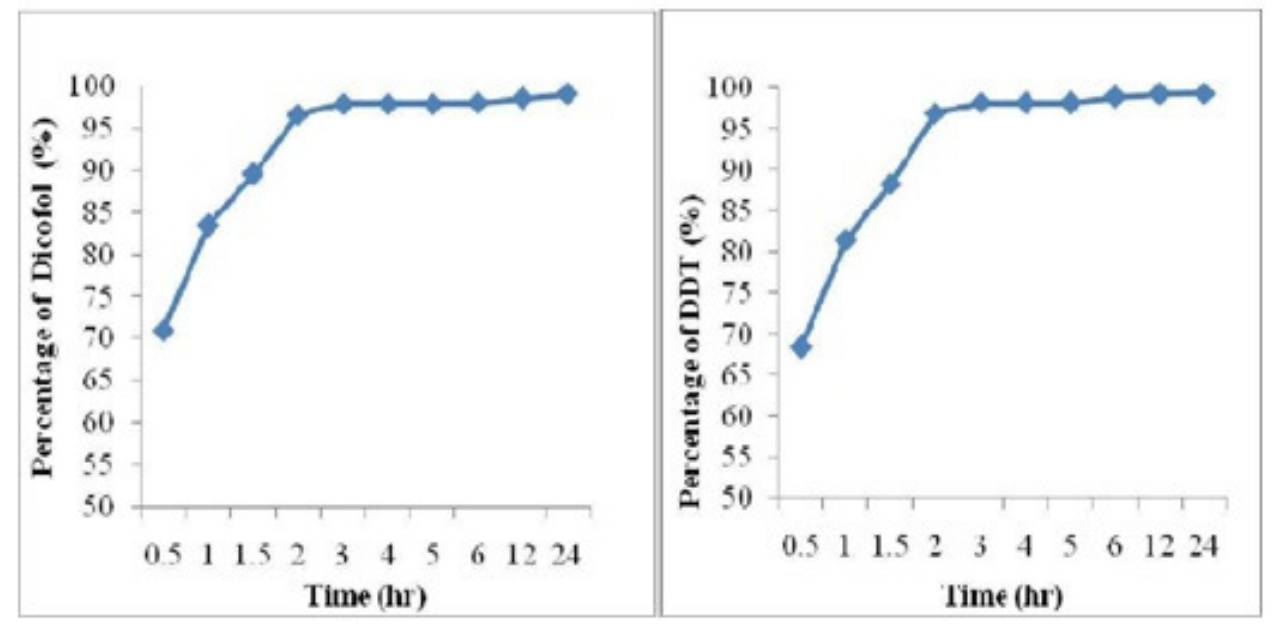

Figure 7. Kinetic curve for Dicofol and DDT using activated carbon $(8 \times 30)$

\subsubsection{Adsorption Studies}

Langmuir and Freundlich isotherm models were used to describe equilibrium isotherm of adsorption process. Values of Freudlich and Langmuir isotherm constants are shown in table 1.

$\mathrm{R}^{2}$ value is statistical measure of how close the data to the fitted regression line. $K$ is constant indicative of adsorption capacity of the adsorbent $(\mathrm{mg} / \mathrm{g}(\mathrm{L} / \mathrm{mg}) 1 / n), 1 / n$ indicates the intensity of adsorption, $C$ is equilibrium concentration $(\mathrm{mg} / \mathrm{L})[7]$. If $\mathrm{n}$ lies between one and ten, this indicates a favourable sorption process [8]. For Freundlich isotherm model, linear regression

coefficient $\left(\mathrm{R}^{2}\right)$ for Dicofol and DDT were 0.9031 and 0.9034 respectively. Since $\mathrm{R}^{2}$ value is near to unity and $n>1$, Freundlich model best fits the experimental results

Table 1. Correlation coefficients and constants with respect to adsorption equilibrium models

\begin{tabular}{|l|c|c|c|c|c|c|}
\hline Pesticides & \multicolumn{3}{|c|}{ Freundlich model } & \multicolumn{3}{c|}{ Langmuir model } \\
\hline & $\mathrm{R}^{2}$ & $\mathrm{n}$ & $\mathrm{K}$ & $\mathrm{R}^{2}$ & $\mathrm{a}$ & $\mathrm{b}$ \\
\hline Dicofol & 0.9031 & 9.84 & 0.4003 & 0.689 & -142.85 & -0.07 \\
\hline p,p'-DDT & 0.9034 & 9.95 & 0.4046 & 0.359 & -500 & -0.041 \\
\hline
\end{tabular}

\subsubsection{Column Study}

Column study was conducted to evaluate the capacity of $(8 \times 30)$ granular activated carbon for removing pesticides from the synthetic effluent which had been treated by solvent extraction process using the solvent- MCB. Influent concentration of Dicofol and DDT were $21.975 \mathrm{ppb}$ and $10.044 \mathrm{ppb}$ respectively. Study was conducted for a duration of $24 \mathrm{hrs}$ and at $24 \mathrm{hr}$, concentration 
of dicofol and DDT were only 3.65 and 1.983 respectively when the allowed limit was 100 microgram and 10 microgram respectively. Adsorption technique alone had a percentage reduction of $83.39 \%$ and $80.25 \%$ for Dicofol and DDT respectively. Hence the activated carbon ( $8 \times 30)$ was a good adsorbent and is very efficient in removing pesticides from water. Pesticide concentration at different stage of treatment is shown in the table 2 .

Table 2. Concentration of pesticides after solvent extraction and adsorption technique

\begin{tabular}{|l|c|c|c|}
\hline Pesticides & $\begin{array}{c}\text { Initial } \\
\text { Concentration(ppb) }\end{array}$ & $\begin{array}{c}\text { Concentration after solvent } \\
\text { Extraction(ppb) }\end{array}$ & $\begin{array}{c}\text { Concentration after } \\
\text { Adsorption(ppb) }\end{array}$ \\
\hline Dicofol & 403 & 21.97 & 3.65 \\
\hline DDT & 93 & 10.04 & 1.98 \\
\hline
\end{tabular}

\subsubsection{SEM Images.}

Samples of adsorbent were taken before and after adsorption and were analyzed using a scanning electron microscope [SEM] in order to confirm pesticides adsorption in activated carbon, The SEM photographs of adsorbents before and after adsorption are shown in figures 8 and 9. From the figures, it is clear that there is significant change in the appearance of the adsorbent surface.

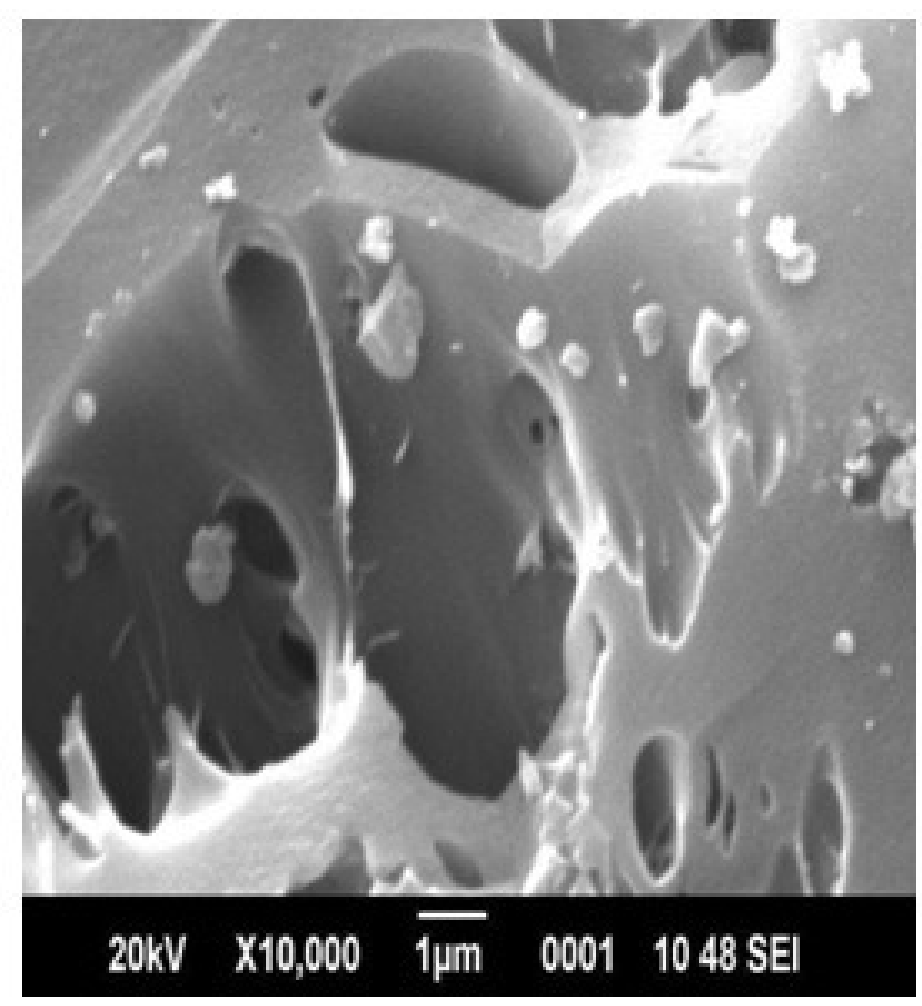

Figure 8. SEM image of activated carbon before pesticide adsorption. 


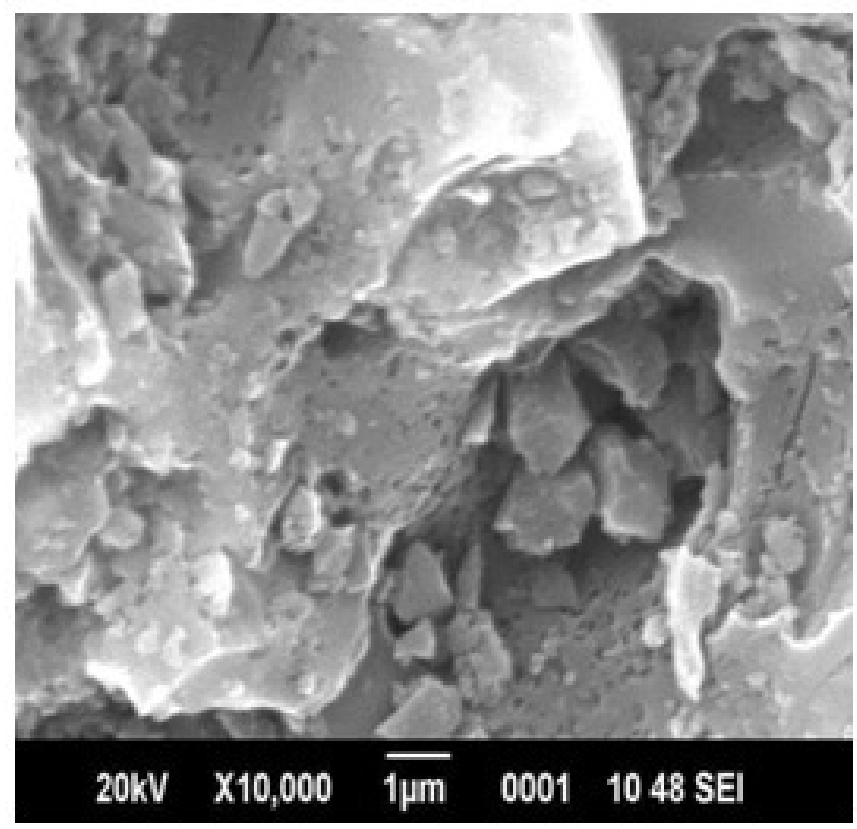

Figure 9. SEM image of activated carbon after pesticide adsorption.

\section{CONCLUSION}

The present study was conducted for the estimation of removal efficiencies of the pesticides Dicofol and DDT using solvent extraction and adsorption technique. In solvent extraction process, 3 solvents like monochlorobenzene (MCB), Ethylene dichloride (EDC) and hexane were selected for the optimisation study as these solvents are easily available and economical. These solvents can be reused after distillation process and therefore overall cost of the treatment is less. The parameters considered in the optimisation studies were agitation speed, agitation time, effluent to solvent ratio and settling time. By considering all these parameters for all the three solvents, MCB was found to be the best solvent as it had higher percentage removal efficiency of about $94.54 \%$ and $89.2 \%$ for Dicofol and DDT respectively.During adsorption study, three types of activated carbon( $8 \times 30,12$ x 40, and -100 US MESH) were selected, out of which activated carbon ( 8 X 30) was identified as the best adsorbent for the adsoption study. Optimised amount of carbon was found to be $2 \mathrm{gm} / 100 \mathrm{ml}$. Kinetic study was conducted for determining the equilibrium time required for the maximum adsorption of the pesticides (Dicofol and DDT) in $8 \times 30$ granular activated carbon. The optimum time for adsorption was found to be $3 \mathrm{hrs}$ each for Dicofol and DDT.

The well-known Freundlich and Langmuir isotherm were applied for the equilibrium adsorption data and various isotherm parameters were evaluated. Among the two isotherms, Freundlich best fits the experimental results and shows that the adsorption is progressive. A column study was also conducted using the selected activated carbon as tertiary treatment after solvent extraction to test the scope for complete removal of pesticides. After column study, concentration of pesticide effluent after solvent extraction can be brought down from $21.97 \mathrm{ppb}$ to $3.65 \mathrm{ppb}$ for Dicofol and $10.04 \mathrm{ppb}$ to $1.98 \mathrm{ppb}$ for p.p'-DDT. Thus the concentration of pesticide was within the 
permissible limit after adsorption technique when the allowed limit of Dicofol and DDT were 100 $\mathrm{ppb}$ and $10 \mathrm{ppb}$ respectively. Therefore, the activated carbon (8 x 30) was a good and efficient adsorbent for the removal of above pesticides from water. Data obtained in this study indicates that the process of solvent extraction alone can't bring the pesticide concentration within the permissible limit, but the combination of solvent extraction process and adsorption technique can achieve a higher removal efficiency of $99.09 \%$ for Dicofol and $97.86 \%$ for DDT.

\section{ACKNOWLEDGEMENTS}

I extend my sincere thanks to Unit Head, all staffs in R \& D and other departments of Hindustan Insecticide Limited, Kochi for their timely help and support throughout the project. Also, I thank all the teachers of SCMS School of Engineering and Technology, Karukutty, Kochi.

\section{REFERENCES}

[1] EPA, "Solvent Extraction Of Wastewater From Acetic Acid Manufacture", April 1980, EPA600/2-80 - 064

[2] Kiezyk and Mackay (1971) - Waste water treatment by solvent extractionll, The Canadia Journal of Chemical Engineering, Volume 49, Issue 6, pages 747-752.

[3] Rao, Reddy, Venkateswarlu, Seshaiah (2009) — Removal of mercury from aqueous solutions using activated carbon prepared from agricultural byproduct/waste" J Enviro Manage 90: 634-643.

[4] Gupta V.K and Imran A (2001), - Removal of DDD and DDE from waste water using baggasses fly ash sugar industry wastell, Water Res., 35, 33e-40

[5] Gupta V.K, Jain C.K, Imran A. and Chanda S (2002) - Removal of Lindane and malathion from waste water using baggaaae fly ash : A sugar industry wastell Water Res.,3, 2483e-2490.

[6] Sheha R.R and Metwally E (2009) "Equilibrium isotherm modeling of cesium adsorption onto magnetic materials\|, J. Hazard. Mater., 143, 354-361

[7] Muhammad Zahoor (2013) - Removal of Pesticides from Water Using Granular Activate Carbon and Ultrafiltration Membrane-A Pilot Plant Studyll, Journal of Encapsulatio and Adsorption Sciences, pp 71-76.

[8] Goldberg -Equations and Models Describing Adsorption Processes in Soilsl, Soil Science Society of America, 677 S. Segoe Road, Madison, WI 53711, USA, Chemical Processes in Soils. SSSA Book Series (2005) no. 8.

\section{AUTHORS}

Aswathy Rajan - Completed B Tech in Civil Engineering from Saintgits College of Engineering, Pathamuttom, Kottayam and pursuing $M$ Tech in Environmental Engineering from SCMS School of Engineering And Technology, Karukutty, Cochin.

Sanju Sreedharan, has been working as Faculty, in Civil Engineering Department of SCMS School of Engineering and Technology, Karukutty, Kerala since 2005. For the last 3 years, she is also associated with SCMS Water Institute - a research and consultancy centre on water. She had completed, B Tech Degree in Civil Engineering

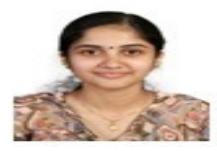
and M Tech Degree in Environmental Engineering from Govt. Engineering College, Thrissur and currently pursuing PhD Degree in Civil- Environmental Engineering at School of Engineering, CUSAT, Kochi.

Dr. V. Babu - Working as a Development Chemist in R \& D Department, Hindustan Insecticide Limited, Cochin. Completed Phd from CUSAT and have 27 years R \& D experience in Hindustan Insecticide Limited, Cochin. 